\title{
Erweiterung des Treuhandpartnernetzes im Kanton Bern
}

FMH Consulting Services bietet ab 1. Oktober 2006 mit der Blaser Treuhand AG, Bern, einen weiteren Treuhandpartner in ihrem Netz an.

Die Blaser Treuhand AG wurde vor 21 Jahren von Urs Blaser, dipl. Experte in Rechnungslegung und Controlling, gegründet. Die in der Stadt Bern domizilierte Treuhandgesellschaft beschäftigt heute 14 Mitarbeiter/innen und tritt neu zusätzlich als Vertrauenspartner FMH Treuhand Services am Markt auf. Treuhandexperte, Steuerberater und Wirtschaftsprüfer finden sich bei der Blaser Treuhand AG unter einem Dach zusammen. Mit weiteren gut ausgebildeten Mitarbeiter/innen (eidg. Fachausweise) ermöglichen sie eine umfassende und tiefgehende Beratung in den Bereichen Steuern und Abschlussberatung, betriebswirtschaftliche Lösungen und Finanzen. Im beliebigen Umfang übernehmen sie auch die Buchführung und Saläradministration für ihre Klienten.

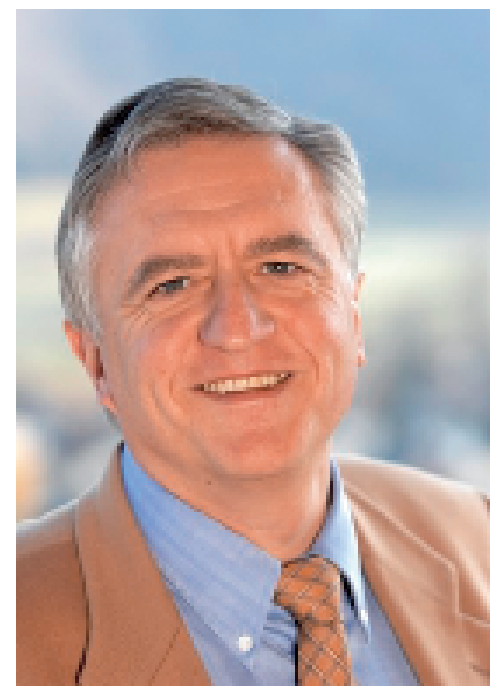

Urs Blaser besitzt einen reichen Wissens- und Erfahrungsschatz als Treuhänder, den er gerne zu Ihren Gunsten einsetzt. Als langjähriger Berater unzähliger Ärzte/Zahnärzte und weiterer KMU-Firmen verfügt Urs Blaser über fundierte Kenntnisse der finanziellen Zusammenhänge, insbesondere auch im Gesundheitswesen.

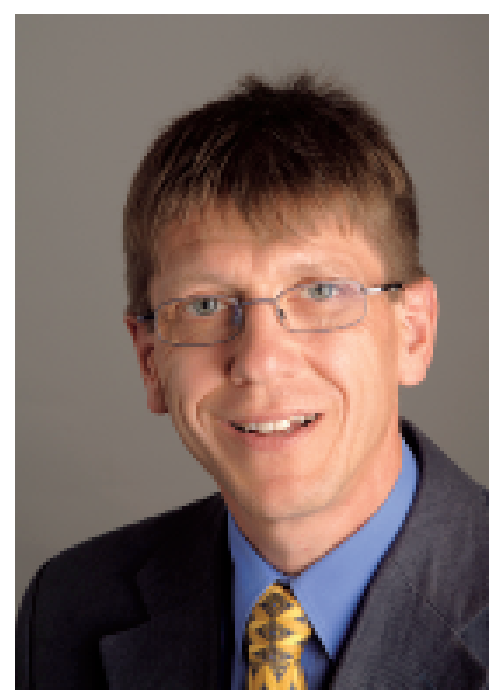

Christian Flury stiess vor zehn Jahren zum Team der Blaser Treuhand AG. Er ist ausgebildeter Treuhänder mit eidg. Fachausweis und dipl. Wirtschaftsprüfer. Auch er schaut auf eine mehr als 20jährige Treuhandkarriere zurück. Er hat mehrjährige Erfahrung in der Betreuung von Ärztinnen und Ärzten. Christian Flury kann dank seiner Sprachkenntnisse auch Mandate in Französisch und Englisch betreuen.

Im Bereich Rechtsberatung und bei der Erarbeitung von Versicherungslösungen arbeitet die Blaser Treuhand AG mit einem bewährten Netzwerk von Spezialisten (Notare, Anwälte, Versicherungsberater) zusammen.

Das Dienstleistungsangebot reicht von der Gründungsberatung bis zur Begleitung der Geschäftsaufgabe bzw. übergabe. Mit Fragen zur Steuerplanung, Finanzplanung, Finanzierungsberatung und zu weiteren betriebswirtschaftlichen Aufgaben sind Sie bei der Blaser Treuhand AG gut aufgehoben. Dasselbe gilt, wenn Sie sich in der Administration, z.B. der Buchhaltung, Steuerdeklaration oder Saläradministration, entlasten und die Arbeiten in kompetente Hände legen wollen.

Wir sind gerne für Sie da! Auf Ihren Anruf freut sich

\section{Blaser Treuhand AG \\ FMH Treuhand Services}

Weissenbühlweg 26 - $\mathrm{CH}$-3007 Bern

Tel. 0313701120 a Fax 0313714518 